\title{
Alzheimer's Disease: Can the Meningeal Lymphatics Provide the Answer?
}

\author{
Stanley G. Rockson, MD
}

$\mathbf{T}$

HE LONG-HELD CONVICTION that the lymphatic circulation does not play a role in the central nervous system has recently been overturned by the discovery of a robust meningeal lymphatic system. ${ }^{1-3}$ This newly identified, so-called "glymphatic system" has proven to be a significant pathway for lymph drainage pathway that provides a dynamic connection between the cerebrospinal and peripheral interstitial fluid compartments.

Identification of the glylymphatic system immediately and naturally prompts the question whether this system might play a significant role in the largely unresolved problem of neurodegenerative pathologies, including Alzheimer's disease. ${ }^{1}$ This highly prevalent disorder is ta profound source of functional cognitive decline with tremendous socioeconomic implications; satisfactory insights are nearly wholly lacking.

The specific role of the central nervous system lymphatics in the pathogenesis of Alzheimer's disease might reside in their participation in altered clearance of amyloid beta proteins, whose spontaneous plaque-like aggregation in the tissues of the brain represent the hallmark of the disease.

In this issue of Lymphatic Research and Biology, Dupont et al. provide a cogent and timely review of the potential relationships between central nervous system lymphatic function and the pathogenesis of, and potential therapeutic implications for, Alzheimer's disease. Here they summarize the molecular mechanisms whereby the amyloid beta protein may find access into this drainage pathway to successfully enter the blood-brain barrier.

The potential to augment protein clearance from the brain through the glylymphatic system represents an exciting avenue of hope for the Alzheimer patient community, and represents another highly significant aspect of the lymphatic continuum. ${ }^{4,5}$

\section{References}

1. Louveau A, Smirnov I, Keyes TJ, Eccles JD, Rouhani SJ, Peske JD, Derecki NC, Castle D, Mandell JW, Lee KS, Harris TH, Kipnis J. Structural and functional features of central nervous system lymphatic vessels. Nature 2015; 523:337-341.

2. Engelhardt B, Carare RO, Bechmann I, Flügel A, Laman JD, Weller RO. Vascular, glial, and lymphatic immune gateways of the central nervous system. Acta Neuropathol 2016; 132:317-338.

3. Plog BA, Nedergaard M. The glymphatic system in central nervous system health and disease: Past, present, and future. Annu Rev Pathol 2018; 13:379-394.

4. Rockson SG. The lymphatic continuum revisited. Ann N Y Acad Sci2008; 1131:ix-x.

5. Rockson SG. Cancer is part of the lymphatic continuum. Lymphat Res Biol 2012; 10:95. 